Article Review

\title{
Aspek Budaya dan Sosial dalam Komunikasi dan Profesionalisme Medis
}

\author{
Astrid Pratidina Susilo ${ }^{1 *}$ \\ ${ }^{1}$ Fakultas Kedokteran Universitas Surabaya, Surabaya-Indonesia \\ * corresponding author: pratidina@gmail.com
}

\begin{abstract}
Medical communication and professionalism are central issues in clinical practice. Both are highly influenced by context such as cultural and social aspects. In medical education, a lot of studies about communication and professionalism have been conducted in Western setting and may not be fully applicable for other cultural or social context. This article aims to introduce several evidence from non-Western context in the area of medical communication and professionalism and discuss their applicability. We will use the study from Hofstede et al. about cultural domains as a theoretical basis. We will also present different studies on communication and professionalism conducted in Asia, such as from Indonesia and Japan, highlight some differences, and discuss how they may influence the medical communication and professionalism. We will provide practical examples on how to use these body of evidence in communication skills training and other area of medical education. Finally, we will discuss some ideas to strengthen future research initiatives from our context.
\end{abstract}

Keywords: asia, communication, culture, medical education, professionalism

\begin{abstract}
Abstrak-Komunikasi medis dan profesionalisme adalah masalah sentral dalam praktik klinis. Keduanya sangat dipengaruhi oleh konteks seperti aspek budaya dan sosial. Dalam pendidikan kedokteran, penelitian tentang komunikasi dan profesionalisme banyak dilakukan dalam konteks budaya Barat, dan mungkin tidak sepenuhnya dapat diterapkan untuk konteks budaya atau sosial lainnya. Artikel ini bertujuan untuk memperkenalkan beberapa bukti dari konteks non-Barat di bidang komunikasi medis dan profesionalisme serta membahas penerapannya. Penelitian dari Hofstede et al. tentang ranah budaya akan digunakan sebagai dasar teoritis. Artikel ini juga akan menyajikan berbagai studi tentang komunikasi dan profesionalisme yang dilakukan di Asia, seperti dari Indonesia dan Jepang, menyoroti beberapa perbedaan, dan membahas bagaimana pengaruhnya terhadap komunikasi medis dan profesionalisme. Beberapa contoh praktis tentang bagaimana menggunakan bukti-bukti ini dalam pelatihan keterampilan komunikasi dan bidang pendidikan kedokteran lainnya akan diberikan. Terakhir, kami akan membahas beberapa ide untuk memperkuat inisiatif penelitian di masa depan dari konteks Indonesia.
\end{abstract}

Kata kunci: asia, komunikasi, budaya, pendidikan kedokteran, profesionalisme

\section{PENDAHULUAN}

Komunikasi medis dan profesionalisme adalah isu sentral dalam praktek klinis (Silverman et al., 2005). Keduanya sangat dipengaruhi oleh konteks, seperti aspek sosial dan budaya (Claramita dan Susilo, 2014; Susilo, 2013).

Dalam pendidikan kedokteran, banyak studi tentang komunikasi dan profesionalisme telah dilakukan dalam konteks budaya Barat (Silverman et al., 2005). Hasilnya mungkin tidak sepenuhnya dapat diterapkan untuk konteks budaya atau sosial lainnya (Claramita, 2012). Artikel ini bertujuan untuk memperkenalkan beberapa bukti dari konteks Asia (non-Barat) di bidang komunikasi medis dan profesionalisme dan membahas penerapannya.

\section{Konteks Budaya dan Sosial Asia}

Meskipun kondisi budaya dan sosial beragam di berbagai negara Asia, ada beberapa kesamaan yang dimiliki (Acuin et al., 2011; Chongsuvivatwong et al., 2011). Menurut Hofstede (2010), seorang peneliti dari Belanda, budaya diartikan sebagai program kolektif dari pikiran yang membedakan anggota satu kelompok atau kategori orang dari kelompok lain. Hofstede mengidentifikasi enam ranah budaya yang dapat diukur menggunakan indeks, yaitu Power-Distance Index (PDI), Individualism Index (IDV), Masculinity dan Feminity Index (MAS), Uncertainty Avoidance Index (UAI), Short/Long Term Orientation (STO/LTO), Indulgence Versus Restraint Index (IVR). Elaborasi tiap indeks tidak menjadi fokus dari artikel ini dan pembaca dapat merujuk ke referensi lebih lanjut (Hofstede et al, 2010). Setiap ranah budaya memiliki suatu kontinuitas. Sebagai contoh, suatu bangsa dapat memiliki kecenderungan lebih berorientasi jangka panjang atau lebih berorientasi jangka pendek. Dengan menggunakan indeks, kita dapat memahami posisi negara tertentu pada titik 
tertentu sepanjang kontinuitas ini (Hofstede et al., 2010).

Secara umum, negara-negara di Asia memiliki PDI yang tinggi (hierarkis) dan IDV yang rendah (komunal). Budaya hierarki yang kuat tercermin pada jarak kekuasaan yang lebar antar manusia, misalnya antara orang tua dan anak, atau guru dan siswa. Budaya komunal yang kuat mengacu pada pengaruh dominan komunitas, atau kelompok, terhadap individu. Karakteristik ini memengaruhi berbagai aspek kehidupan manusia termasuk praktik sehari-hari dalam pelayanan kesehatan (Hofstede et al., 2010).

Karena pengaruh sosial sangat luas, dalam artikel ini aspek "sosial" dibatasi pada sistem pelayanan kesehatan. Banyak negara di Asia menghadapi kekurangan dan distribusi tenaga kesehatan yang tidak merata (Kanchanachitra et al., 2011; Shields dan Hartati, 2003). Standardisasi kompetensi profesional kesehatan di berbagai negara masih menjadi tantangan. Di Indonesia, peningkatan standardisasi di lebih dari 80 sekolah kedokteran dan 600 sekolah perawat masih menjadi perjuangan (Kanchanachitra et al., 2011; Shields dan Hartati, 2003). Selain itu, sistem pembiayaan pelayanan kesehatan juga berpengaruh. Cakupan pelayanan kesehatan universal telah diterapkan di beberapa negara di Asia, sementara negara lain sedang berjuang dalam fase implementasi (Tangcharoensathien et al., 2011).

\section{Komunikasi Medis dalam konteks Asia}

Karakteristik unik dari aspek budaya dan sosial tercermin dalam pelayanan kesehatan. Hal ini terlihat dari semakin banyak hasil penelitian di bidang komunikasi medis dan profesionalisme yang dilakukan di Asia (Claramita, 2012; Nishigori et al., 2014; Pun et al., 2018; Susilo, 2013).

Claramita dan Susilo melaporkan beberapa temuan terkait budaya dalam komunikasi dokter-pasien di Asia Tenggara. Pertama, pasien menggunakan pengobatan tradisional secara ekstensif. Mereka memperoleh informasi tentang pengobatan tradisional dari keluarga dan masyarakat. Ini adalah refleksi dari budaya komunal (Claramita dan Susilo, 2014). Kedua, pasien ragu untuk menyampaikan keprihatinan atau ketidaksepakatan mereka kepada tenaga kesehatan. Hal ini terkait dengan budaya hierarki yang kuat di mana para profesional kesehatan umumnya dipandang berada di tingkat hierarki sosial yang lebih tinggi (Susilo, 2013). Namun, pasien tetap berharap untuk dipertimbangkan pendapatnya dalam pengambilan keputusan medis (Claramita et al., 2011). Oleh karena itu, tenaga kesehatan harus dapat menggali keprihatinan pasien, misalnya dengan peka terhadap isyarat nonverbal halus dari pasien (Claramita et al., 2013b). Ketiga, sebagai ciri budaya komunal, pengaruh keluarga dalam pengambilan keputusan pasien sangat kuat. Kadang-kadang, hal itu dapat mengesampingkan otonomi pasien dan mengancam keselamatan pasien (Claramita et al., 2013a; Susilo et al., 2012). Oleh karena itu tenaga kesehatan harus dapat memberikan kesempatan kepada pasien untuk mengungkapkan keinginannya yang mungkin berbeda dengan keinginan keluarganya (Susilo et al., 2013).

Dalam budaya hierarki yang kuat, peran advokat pasien dapat membantu memastikan otonomi dan keamanan pasien. Misalnya perawat dapat membantu menjembatani kesenjangan antara dokter dan pasien dengan mengeksplorasi keprihatinan pasien yang tidak terucapkan, membantu pasien untuk merumuskan pertanyaan yang sesuai, dan menyampaikan pertanyaan ini kepada dokter mereka. Posisi ini juga dapat dijabat oleh tenaga kesehatan lainnya, misalnya oleh apoteker atau oleh sesama dokter (Susilo et al., 2013).

Namun demikian, ada tantangan untuk mengambil peran advokasi ketika budaya hierarkis mempengaruhi hubungan interprofesional. Seorang perawat, misalnya, dapat memilih untuk tidak menjadi advokat bagi pasien ketika mereka juga memandang bahwa dokter berada di tingkat yang lebih tinggi dalam hierarki sosial. Dalam situasi seperti ini, otonomi dan keselamatan pasien terancam (Susilo et al., 2013).

Tantangan ini menjadi lebih besar karena ada bagian sistem layanan kesehatan yang kurang mendukung. Kekurangan jumlah dan distribusi tenaga kesehatan tidak merata 
mengakibatkan beban kerja meningkat. Dokter sering kali memiliki waktu terbatas untuk konsultasi klinis (Claramita et al., 2011). Perawat juga dilaporkan terbebani oleh tugas klinis yang berbeda (Susilo et al., 2013). Penelitian sebelumnya juga menemukan bahwa tenaga kesehatan tidak siap dalam pendidikan mereka untuk berkomunikasi dengan baik dengan pasien atau bertindak sebagai advokat pasien. Masalah yang terkait dengan sistem ini berdampak pada hubungan antara pasien dan profesional kesehatan dalam praktik klinis sehari-hari (Bartholomew et al., 2011; Susilo et al., 2012).

\section{Profesionalisme Medis dalam Konteks Asia}

Di bidang profesionalisme medis, sebuah studi dari Nishigori et al. menguraikan konsep profesionalisme di Jepang. Mereka menerapkan prinsip Bushido, yang merupakan kebajikan samurai Jepang, ke dalam profesionalisme medis. Salah satunya, chu-gi, artinya kesetiaan, sangat dipengaruhi oleh budaya komunal. Nishigori menggarisbawahi bahwa dokter di Jepang memiliki in group bounding yang sangat kuat. Mereka menempatkan kebutuhan kelompok di atas kebutuhan dan minat mereka sendiri. Inilah salah satu ciri yang berbeda antara budaya Asia dan Barat (Nishigori et al., 2014).

Pilihan untuk melakukan advokasi juga merupakan cerminan dari profesionalisme medis. Ketika seorang profesional kesehatan melihat suatu kondisi yang mengancam otonomi pasien, mereka memiliki pilihan untuk berespons. Seseorang mungkin mengambil peran sebagai advokat dan mendukung pasien. Profesional kesehatan yang lain mungkin memilih untuk mengabaikan kepentingan pasien, terutama jika peran advokasi dapat membuat dirinya berada pada posisi yang tidak nyaman. Seperti disebutkan di atas, pilihan ini sering dipengaruhi oleh hierarki (Susilo, 2013; Vaartio dan Leino-Kilpi, 2005).

\section{Bagaimana Kita Mempersiapkan Profesional Kesehatan?}

Pendidikan sangat penting untuk mempersiapkan tenaga kesehatan menghadapi tantangan budaya dan sosial dalam praktek klinis sehari-hari. Keterampilan komunikasi harus dilatih secara longitudinal sepanjang kurikulum pendidikan, diintegrasikan dengan pembelajaran kasus klinis, dan pengenalan sisi etika dan hukum dari kasus tersebut (Susilo et al., 2013). Pelatihan keterampilan komunikasi juga dapat berperan sebagai alat untuk menumbuhkan profesionalisme mahasiswa. Refleksi dan umpan balik harus menjadi dasar dari proses pembelajaran ini (Silverman et al., 2005; Susilo et al., 2013).

Untuk menjawab tantangan sosial budaya, beberapa inisiatif telah dilakukan. Sebuah pedoman bernama Greet-Invite-Discuss (Sapa-Ajak Bicara-Diskusikan) diperkenalkan untuk melatih keterampilan komunikasi dokter-pasien dalam konteks Asia Tenggara. Pedoman ini didasarkan pada temuan budaya yang khas untuk konteks ini. Beberapa ciri khusus dalam pedoman ini adalah profesional didorong untuk menghormati pasien dalam penggunaan obat tradisional dan mempertimbangkan keterlibatan keluarga dalam pengambilan keputusan (Claramita et al., 2013b).

Alat bantu pendidikan lainnya, Leary's Rose, juga digunakan dalam pelatihan keterampilan komunikasi interprofesional. Alat ini membantu memetakan negosiasi antar pihak dalam hubungan hierarkis. Dengan memahami posisi masing-masing pihak, seseorang dapat mengelola hubungan hierarkis, menjaga kesetaraan dalam interaksi, menghindari komunikasi yang berkecenderungan untuk saling menyalahkan, dan membangun kolaborasi (Susilo et al., 2013). Alat bantu pendidikan ini telah diujicobakan dalam pelatihan keterampilan komunikasi dalam konteks interprofesional (Susilo et al., 2014).

Namun demikian, karena budaya dan sistem sosial berbeda dari satu tempat ke tempat lain, tidak mungkin untuk mempelajari semua variasi tersebut. Proses pendidikan harus mampu mengembangkan kompetensi budaya peserta didik. Kompetensi budaya dapat dipahami sebagai keterampilan yang dipelajari yang membantu memahami perbedaan budaya dan memudahkan komunikasi dengan beragam pasien yang memiliki cara berbeda dalam 
memahami kesehatan dan penyakit. Bersama dengan pelatihan keterampilan komunikasi medis dan profesionalisme, pengembangan kompetensi budaya harus diintegrasikan dalam kurikulum profesional kesehatan di sepanjang kurikulum (Beach et al., 2005).

\section{Memperkuat Inisiatif Penelitian Masa Depan}

Masih banyak lagi penelitian tentang komunikasi dan profesionalisme dalam konteks Asia yang belum dielaborasi dalam artikel ini. Kajian sistematis dari publikasi terkait komunikasi kesehatan di Asia Timur telah diterbitkan baru-baru ini dan ulasan ini telah menambahkan bukti yang signifikan (Pun et al., 2018).

Contoh-contoh dalam artikel ini hanya menyentuh dua dari enam ranah budaya dalam kerangka teori Hofstede. Di masa depan, banyak penelitian yang perlu dilakukan untuk mengelaborasi pengaruh ranah lain pada komunikasi dan profesionalisme medis. Selain itu, penelitian kolaboratif juga dibutuhkan untuk mengelaborasi pengaruh aspek budaya dan sosial di Asia dan mendukung pembelajaran para profesional kesehatan di bidang ini.

\section{Kesimpulan}

Komunikasi medis dan profesionalisme sangat dipengaruhi oleh aspek budaya dan sosial. Profesional kesehatan harus menyadari pengaruhnya dan mampu mempertimbangkannya dalam praktik klinis. Pendidikan memiliki peran penting dalam mempersiapkan profesional kesehatan sehingga harus dikelola secara sistematis dalam kurikulum. Di masa yang akan datang, dibutuhkan lebih banyak penelitian dalam bidang ini.

\section{PUSTAKA ACUAN}

Acuin, J, Firestone, R, Htay, T.T, Khor, G.L, Thabrany, H, Saphonn, V \& Wibulpolprasert, S (2011). 'Southeast Asia: an emerging focus for global health', The Lancet, 377, 534-535.

Bartholomew, L.K, Parcel, G.S, Kok, G, Gottlieb, N.H \& Fernandez, M.E (2011),'Planning health promotion programs: An intervention mapping approach,Jossey-Bass.

Beach, M.C, Price, E.G, Gary, T.L, Robinson, K.A, Gozu, A, Palacio, A, Smarth, C, Jenckes, M.W, Feuerstein, C, Bass, E.B, Powe, N.R \& Cooper, L.A (2005),'Cultural competency: A systematic review of health care provider educational interventions', Medical Care, 43, 356-373.

Chongsuvivatwong, V, Phua, K.H, Yap, M.T, Pocock, N.S, Hashim, J.H, Chhem, R, Wilopo, S.A \& Lopez, A.D (2011). Health and health-care systems in southeast Asia: diversity and transitions. The Lancet 377, 429-437.

Claramita, M (2012),'Doctor-patient communication in a culturally hierarchical context of Southeast Asia: a partnership approach', [Dissertation] Maastricht University, Maastricht.

Claramita, M, Nugraheni, M.D, van Dalen, J \& van der Vleuten, C (2013),'Doctor-patient communication in Southeast Asia: a different culture?',Adv Health Sci Educ Theory Pract, 18, 15-31.

Claramita, M \&Susilo, A.P (2014), 'Improving communication skills in the Southeast Asian health care context'.Perspect Med Educ,3, 474-479.

Claramita, M, Susilo, A.P, Kharismayekti, M, van Dalen, J, \& van der Vleuten, C (2013)b,'Introducing a partnership doctor-patient communication guide for teachers in the culturally hierarchical context of Indonesia',Educ Health, 26, 147-155.

Claramita, M, Utarini, A, Soebono, H, van Dalen, J \& van der vleuten, C (2011),'Doctor-patient communication in a Southeast Asian setting: the conflict between ideal and reality', Adv Health Sci Educ Theory Pract,16, 69-80.

Hofstede, G, Hofstede, G.J \& Minkov, M (2010),Cultures and Organizations: software of the mind: intercultural cooperation and its importance for survival, McGraw Hill, New York.

Kanchanachitra, C, Lindelow, M, Johnston, T, Hanvoravongchai, P, Lorenzo, F.M, Huong, N.L, 
Wilopo, S.A \& dela Rosa, J.F (2011),'Human resources for health in southeast Asia: shortages, distributional challenges, and international trade in health services', The Lancet, 377, 769-781.

Nishigori, H, Harrison, R, Busari, J \& Dornan, T 2014,'Bushido and medical professionalism in Japan'Acad Med,89, 560-563.

Pun, J.K.H, Chan, E.A, Wang, S \& Slade, D (2018), 'Health professional-patient communication practices in East Asia: An integrative review of an emerging field of research and practice in Hong Kong, South Korea, Japan, Taiwan, and Mainland China',Patient Educ and Couns,101, 1193-1206.

Shields, L \& Hartati, L.E (2003),'Nursing and health care in Indonesia',J of Adv Nurs, 44, 209216.

Silverman, J, Kurtz, S.M, Draper, J, van Dalen, J, Platt, F.W (2005),Skills for communicating with patients, Radcliffe Pub, Oxford, UK.

Susilo, A.P (2013),'Learning to be the patient advocate: The development of a communication skills course to enhance nurses' contribution to the informed consent process' [Dissertation].,Maastricht University, Maastricht.

Susilo, A.P, van Dalen, J, Scherpbier, A, Tanto, S, Yuhanti, P \& Ekawati, N (2013),'Nurses' roles in informed consent in a hierarchical and communal context',Nurs Ethics, 20, 413-425.

Susilo, A.P, van Merriënboer, J, van Dalen, J, Claramita, M \& Scherpbier, A (2013),'From lecture to learning tasks: Use of the $4 C / I D$ Model in a communication skills course in a continuing professional education context', J Contin Educ Nurs, 44, 278-84.

Susilo, A.P, Claramita, M, van Dalen, J \& Scherpbier, A (2014), 'Learning to be the patients' advocates: Evaluation of an evidence-based communication skills course,South East AsianJ Med Educ, 8, 60-69.

Susilo, A.P, Nurmala, I, van Dalen, J \& Scherpbier, A (2012), 'Patient or physician safety? Physicians' views of informed consent and nurses' roles in an Indonesian setting',J Interprof Care, 26, 212-218.

Susilo, A.P, van Dalen, J, van den Eertwegh, V \& Scherpbier, A (2013),'Leary's Rose to improve negotiation skills among health professionals: Experiences from a Southeast Asian culture', Educ Health 26, 54-59.

Tangcharoensathien, V, Patcharanarumol, W, Ir, P., Aljunid, S.M, Mukti, A.G, Akkhavong, K, Banzon, E, Huong, D.B, Thabrany, H \& Mills, A (2011), 'Health-financing reforms in southeast Asia: challenges in achieving universal coverage', The Lancet, 377, 863-873.

Vaartio, H \& Leino-Kilpi, H (2005),' 'Nursing advocacy-a review of the empirical research 19902003', Int J Nurs Stud, 42, 705-714. 